\title{
Reliable Coding Emerges from Coactivation of Climbing Fibers in Microbands of Cerebellar Purkinje Neurons
}

\author{
Ilker Ozden, ${ }^{1,2 *}$ Megan R. Sullivan, ${ }^{1,2 *}$ H. Megan Lee, ${ }^{2}$ and Samuel S.-H. Wang ${ }^{1,2}$ \\ ${ }^{1}$ Department of Molecular Biology and ${ }^{2}$ Princeton Neuroscience Institute, Princeton University, Princeton, New Jersey 08544
}

\begin{abstract}
The inferior olive projects climbing fiber axons to cerebellar Purkinje neurons, where they trigger calcium-based dendritic spikes. These responses dynamically shape the immediate spike output of Purkinje cells as well as provide an instructive signal to guide long-term plasticity. Climbing fibers typically fire approximately once a second, and the instructive role is distributed over many such firing events. However, transmission of salient information on an immediate basis needs to occur on a shorter timescale during which a Purkinje cell would typically be activated by a climbing fiber only once. Here we show using in vivo calcium imaging in anesthetized mice and rats that sensory events are rapidly and reliably represented by momentary, simultaneous coactivation of microbands of adjacent Purkinje cells. Microbands were sagittally oriented and spanned up to $100 \mu \mathrm{m}$ mediolaterally, representing hundreds of Purkinje cells distributed over multiple folia. Spontaneous and sensory-evoked microbands followed boundaries that were close or identical to one another and were desynchronized by olivary injection of the gap junction blocker mefloquine, indicating that excitation to the olive is converted to synchronized firing by electrical coupling. One-time activation of microbands could distinguish a sensory response from spontaneous activity with up to $98 \%$ accuracy. Given the anatomy of the olivocerebellar system, microband synchrony may shape the output of neurons in the cerebellar nuclei either via powerful inhibition by Purkinje cells or by direct monosynaptic excitation from the inferior olive.
\end{abstract}

\section{Introduction}

The inferior olive is thought to transmit information to the cerebellum and guide movement via the climbing fiber (CF) pathway, which has two major effects on its target, cerebellar Purkinje cells (PCs). The two effects are driven by calcium-based action potentials that occur in the PC dendrite every time the CF fires (Llinás and Sugimori, 1980), triggering widespread dendritic calcium entry and a somatic "complex" spike. First, CF activity immediately modifies the sodium action potential (simple spike) output of the PC (Sato et al., 1992; Simpson et al., 1996). Second, $\mathrm{CF}$ activity also instructs long-term plasticity at synapses that are repeatedly coactivated with the CF (Ito and Kano, 1982; Ito, 2001). Both an instructive and an online role for CF function occur under the constraint that CFs fire approximately once per second, suggesting that information is carried in the timing of complex spikes.

In the case of immediate effects on brain function, models for the role of complex spikes need to be reconciled with the fact that individual PCs do not always respond to single events. Complex

\footnotetext{
Received Feb. 26, 2009; revised June 10, 2009; accepted July 11, 2009.

This work was supported by National Institutes of Health Grant R01 NS045193, a National Science Foundation Career Development Award, a Distinguished Young Investigator Award from the W. M. Keck Foundation, the Human Frontier Science Project, the National Alliance for Autism Research, and the New Jersey Governor's Council on Autism (S.S.-H.W.). We thank S. J. Cruikshank for advice on mefloquine sources, the National Cancer Institute for a gift of mefloquine, J. I. Simpson, E. F. Civillico, T. M. Hoogland, and D. W. Tank for reading this manuscript, and members of the Wang laboratory for advice and discussion.

*I.O. and M.R.S. contributed equally to this work.

Correspondence should be addressed to Samuel S.-H. Wang, Princeton University, Department of Molecular Biology and Princeton Neuroscience Institute, Lewis Thomas Laboratory, Washington Road, Princeton, NJ 08544. E-mail: sswang@princeton.edu.

DOI:10.1523/JNEUROSCI.0967-09.2009

Copyright $\odot 2009$ Society for Neuroscience 0270-6474/09/2910463-11\$15.00/0
}

spike firing occurs only with low probability after single occurrences of any of a variety of sensorimotor events, including facial touch (Brown and Bower, 2001), movements (Welsh et al., 1995; Kitazawa et al., 1998), changes in sensory load (Gilbert and Thach, 1977), and visual feedback error signals (Stone and Lisberger, 1986). Typical single-trial firing probabilities are 0.3 or less (but see Gilbert and Thach, 1977), so that event-related firing consists primarily of shifts in the timing of one complex spike against a continuing background stream of simple and complex spikes. This stream of spikes provides inhibition to the output structures of the cerebellar cortex, the deep nuclei.

One means of distinguishing events from background is synchronization of firing among cells (Singer and Gray, 1995; Hopfield and Brody, 2001). In the cerebellum, natural sensory stimuli (Wylie et al., 1995) and trained movements (Welsh et al., 1995) are associated with increases in complex spike synchrony. This synchrony originates in the inferior olive. Dendrodendritic gap junctions lead neighboring olivary neurons to fire at the same time (Devor and Yarom, 2002; Long et al., 2002), and, in connexin-36 knock-out mice, olivary neurons are desynchronized (Long et al., 2002). CFs from neighboring olivary neurons project in a remarkably precise map to well defined parasagittal zones of Purkinje cells (Apps and Garwicz, 2005; Sugihara and Shinoda, 2007). This mapping suggests that immediately neighboring PCs should show a high degree of simultaneous activation.

In the present work, we measured the representation of sensory events by complex spikes in local ensembles of PCs and the degree to which coactivation contributed to the representations. We monitored cerebellar activity in anesthetized mice and rats 
using two-photon imaging, which can record calcium spike activity in essentially all the PC dendrites in a region of neuropil (Sullivan et al., 2005; Ozden et al., 2008). We found that the degree of coactivation in neighboring PCs is an order of magnitude larger than reported previously from more sparse sampling methods. The strongest coactivation was found under sensory stimulation, indicating that PC ensemble synchrony can convey the occurrence of salient events.

\section{Materials and Methods}

Animal preparation and labeling. Experimental procedures were approved by the Princeton University Institutional Animal Care and Use Committee and performed in accordance with the animal welfare guidelines of the National Institutes of Health. C57BL/6 mice (postnatal day 21-42) or Wistar rats (postnatal day 21-28) were deeply anesthetized with ketamine/xylazine, and a small craniotomy of $2 \mathrm{~mm}$ diameter was made over folium crus IIa. Purkinje cells were loaded with calcium indicator Oregon Green BAPTA-1/AM (Invitrogen) as described previously (Sullivan et al., 2005).

Drug injections and electrophysiology. Mefloquine (National Cancer Institute, Bethesda, MD), a potent blocker of the olivary gap junction connexin36 $\left(\mathrm{IC}_{50}\right.$ of $0.3 \mu \mathrm{M}$ ) (Cruikshank et al., 2004) was dissolved in DMSO $(100 \mathrm{~mm})$, diluted in artificial CSF $(500 \mu \mathrm{M})$, and pressure injected into the inferior olive by a 6-10 $\mathrm{M} \Omega$ saline-filled glass recording micropipette at $1-2 \mathrm{psi}$ for $10 \mathrm{~min}$ at $0.05-0.1 \mu \mathrm{l} / \mathrm{min}$. Harmaline (Sigma), which enhances tremor and provides net excitation to olivary neurons (de Montigny and Lamarre, 1973; Miwa, 2007), was dissolved in sterile saline with acetic acid and given intraperitoneally at a dose of 1 $\mathrm{mg} / \mathrm{kg}$. Extracellular single-unit recordings from Purkinje cells were made using a NeuroData IR-283A amplifier (Cygnus Technology) and glass micropipettes pulled to 6-10 $\mathrm{M} \Omega$ and filled with artificial CSF containing the following (in $\mathrm{mm}$ ): $135 \mathrm{NaCl}, 5.4 \mathrm{KCl}, 5 \mathrm{NaHEPES}, 1$ $\mathrm{MgCl}_{2}$, and $2 \mathrm{CaCl}_{2}, \mathrm{pH} 7.3$ with $\mathrm{HCl}$.

Multiphoton laser scanning microscopy. In vivo calcium imaging was performed using a custom-built multiphoton microscope as described previously (Sullivan et al., 2005; Ozden et al., 2008). Data were collected as movies of $64 \times 64(128 \mathrm{~ms} /$ frame $)$ or $128 \times 128(256 \mathrm{~ms} /$ frame $)$ pixel frames, letterbox scans of $10 \times 128(20 \mathrm{~ms} /$ frame $)$, or line scans at 2 $\mathrm{ms} /$ line. In movies, the fast-scan direction was oriented parasagittally. In letterbox scans, the fast-scan direction was oriented mediolaterally. Distances between dendrites in both mediolateral and rostrocaudal directions were determined from the centroids of the parts of dendrites that were visible within the field of view.

Data analysis. Data analysis was performed as described (supplemental Movies 1-3, available at www.jneurosci.org as supplemental material) (Ozden et al., 2008). All code was written in MATLAB version 7.1 (MathWorks) and is available at http://synapse.princeton.edu/programs.

Temporal correlation-based identification of dendritic arbors. A pixel correlation-based approach was used to exclude less correlated pixels, thereby increasing the likelihood that the final selected pixels belonged to the same cellular structure. Each filtered movie was examined to find candidate dendritic arbors, as judged by the co-occurrence of signals in the shape and orientation of PC arbors and by the criterion that a candidate structure fire by itself and all at once. For each arbor, a region was selected slightly larger than the bright pixels. Pixels were then selected for the final region of interest using a rule requiring each selected pixel to have a correlation value above a threshold $r_{\text {th }}$ with at least $n_{\text {th }}$ pixels in the selected region.

Event detection was done by using a template-and-threshold algorithm on fluorescence traces averaged from the selected region. Each trace was first convolved using a four-point filter taken from the time course of the 10 largest peaks. Then local maxima were classified as events if they exceeded a human user-determined threshold. In experiments in which calcium transients were confirmed as being of climbing fiber origin by simultaneous extracellular recording of complex spikes, the peak $\Delta F / F$ for events was $19.8 \pm 6.9 \%$ in line scans (29 dendrites in four experiments). The peak $\Delta F / F$ was $7.0 \pm 2.8 \%$ ( 817 events) in movies with $256 \mathrm{~ms}$ frame time, as expected (Ozden et al., 2008) and much larger than the background fluctuation of $1.6 \pm 0.4 \% \Delta F / F$ (SD of dendritic fluorescence, mean $\pm \mathrm{SD}, 14$ dendrites). Using these methods, the true-positive rate was $95 \%$, and the false-positive rate was $8 \%$.

In harmaline experiments, event detection was unreliable in frame scans because the frequency of complex spike firing exceeded the frame rate. Therefore, correlations were calculated not from event times, an approach that effectively counts the number of coincident firing events, but directly from continuous fluorescence traces. In fast (line and letterbox) scans in which events were reliably resolved, fluorescence-based correlations showed very similar spatial dependence and patterns compared with event-based correlations.

Likelihood-based correction of event times. For an arbor aligned in the fast-scan direction, a complex spike during scanning of a frame could occur after the beam had already finished scanning the arbor, leading to a one-frame delay in detecting the corresponding calcium transient and thus affecting the detection of simultaneous spike events. Such scan position-dependent error was corrected with a statistical correction of event times (Ozden et al., 2008) to reduce artifactual, apparent distancedependent decreases of correlations when dendrites fire together but are far from one another in the field of view. Every detected peak in sample $i$, which before correction was represented by a value of 1 at one time point in the event trace, was represented by $x / L$ and the $(i-1)$ th time point was set to $1-x / L$, where $x$ is the time from the beginning of the frame for the scan beam to reach the dendrite, and $L$ is the time taken to scan the whole frame.

Meta-k-means (Ozden et al., 2008). In brief, a movie with $M$ arbors and $\mathrm{N}$ time points was represented as $\mathrm{M}$ points in an $\mathrm{N}$-dimensional space, in which each point represents the activity of a single dendritic arbor over the entire movie. The "activity distance" between arbors was defined as $d=1-r$, where $r$ is the Pearson's correlation between activity sequences. $r$ was calculated from corrected event times or, for harmaline experiments, from fluorescence traces. A Pearson's correlation of zero corresponds to the number of simultaneous events that would occur by chance.

For each movie, the $k$-means algorithm (Hartigan and Wong, 1979) was run 1000 times by initializing $k=3$ clusters at random locations in $N$ space, going through a cycle of adding arbors one at a time to the nearest cluster and recalculating the cluster center, and iterating the cycle, starting with the new cluster centers until membership did not change. For each pair of dendritic arbors $i$ and $j$, the number of times arbors $i$ and $j$ were clustered together, $C_{i j}$, was determined. $C$ always had a structure similar to that of the correlation matrix. Working clusters were then defined as the maximum set of arbors such that $C_{i j}$ was $>800$ for every $(i, j)$ within the cluster. This procedure usually found six to eight working clusters in a dataset. Working clusters were then combined iteratively to maximize Dunn's index, which emphasizes individual cluster tightness and the distance between adjacent clusters and is defined as $D I=D_{\min } / d_{\text {max }}$, where $D_{\min }$ is the smallest distance between two points in different clusters, and $d_{\max }$ is the diameter of the widest cluster (Maulik and Bandyopadhyay, 2002). The final clustering did not change with successive runs of meta- $k$-means. In some datasets, meta- $k$-means achieved a higher DI than the most successful single run of $k$-means attributable to the exclusion of outliers.

Event clustering. The correlation between two dendritic signals $x(t)$ and $y(t)$ was calculated as the Pearson's correlation:

$$
r=\frac{\sum_{t} x(t) \cdot y(t)-\langle x\rangle \cdot\langle y\rangle \cdot(\Delta t / T)}{\sqrt{\left[\left\langle x^{2}\right\rangle-\langle x\rangle^{2} \cdot(\Delta t / T)\right] \cdot\left[\left\langle y^{2}\right\rangle-\langle y\rangle^{2} \cdot(\Delta t / T)\right]}}
$$

where $T$ is the total recording time, and $\Delta t$ is the sampling time. For discrete event times,

$$
r=\frac{\left(C-e_{x} \cdot e_{y} / N\right)}{\sigma_{x} \cdot \sigma_{y}},
$$

where $N$ is the number of frames, $C$ is the number of coincidences, $e_{x}=$ $N \cdot p_{x}$ and $e_{y}=N \cdot p_{y}$ are the expected number of events in each dendrite for probabilities $p_{x}$ and $p_{y}, \sigma_{x}=\sqrt{p_{x} \cdot\left(1-p_{x}\right)}$, and 
A
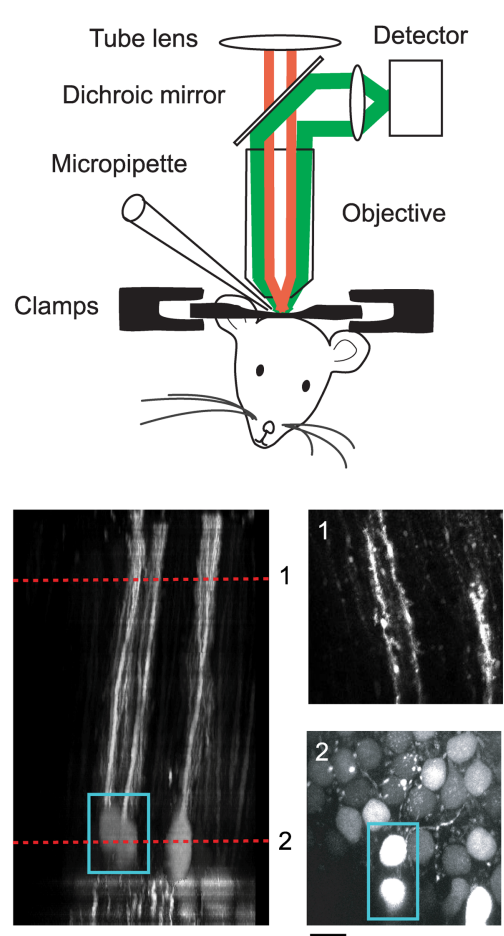

$25 \overline{\mu m}$

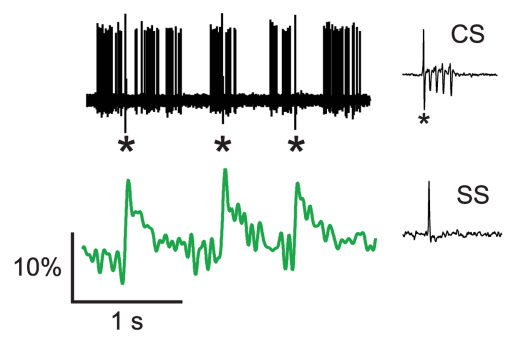

B

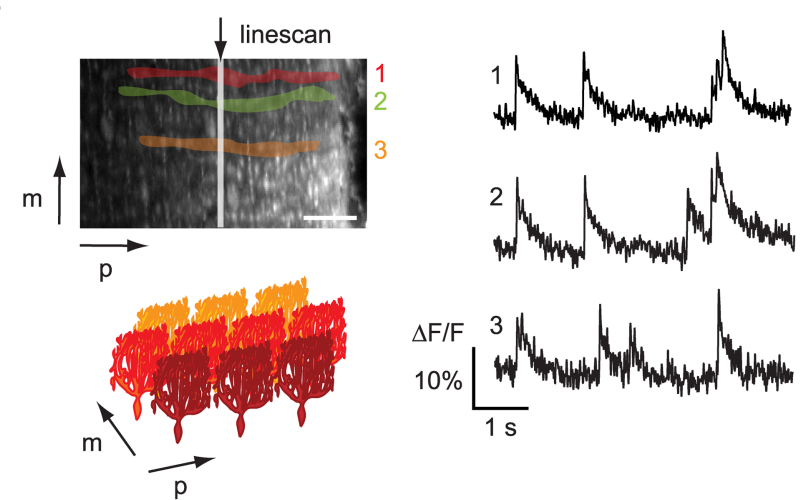

C

Dendrite 1 vs. dendrite 2

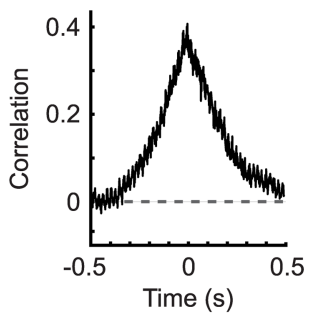

Time of peak correlation

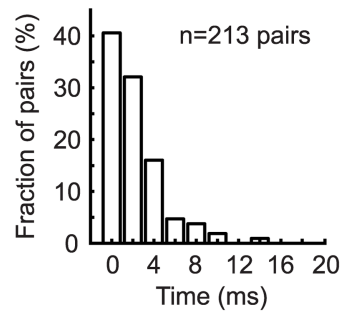

D

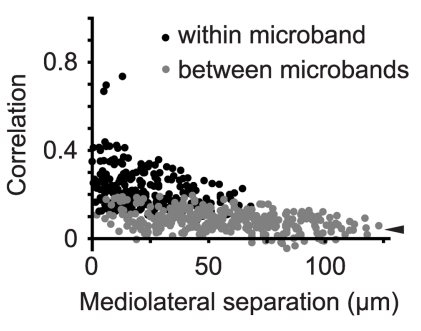

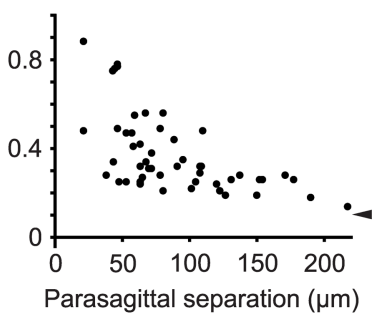

Figure 1. Monitoring the patterns of complex spike activity of many neighboring Purkinje cells. $A, I n$ vivo imaging configuration (top). Reconstructed side views of Purkinje cell dendritic arbors in L7-GFP mice, including two nearest neighbors (middle left). Single sections are demonstrated in the right (middle). An example of simultaneously recorded electrophysiological (black) and calcium-dependent fluorescence change (green) traces (bottom). In electrophysiological trace, asterisks indicate complex spikes (CS) against ongoing simple spike (SS) activity. $\boldsymbol{B}$, Grayscale image of cerebellar neuropil bulk-loaded with Oregon Green BAPTA-1/AM (left top). Three identified dendrites (1-3) are superimposed on the image. Diagram of labeled Purkinje cell arbors showing mediolateral $(\mathrm{m})$ and parasagittal $(\mathrm{p})$ directions (left bottom). A line scan across arbors 1-3 showing synchronous transients (right). C, Cross-correlation of fluorescence signals from arbors 1 and 2 from $\boldsymbol{B}$. Histogram of the timing of the peak correlation (right). $\boldsymbol{D}$, Cross-correlations of event times in pairs of arbors within (black points) and between (gray points) clusters as a function of mediolateral separation from one experiment (left) and as a function of parasagittal separation from three experiments (right).

$\sigma_{y}=\sqrt{p_{y} \cdot\left(1-p_{y}\right)} \cdot r$ is zero when dendrites $x$ and $y$ fire independently and ranges from $-\sqrt{p_{x} \cdot p_{y}\left[\left[\left(1-p_{x}\right) \cdot\left(1-p_{y}\right)\right]\right.}$ (no coincidences) to 1 (identical sequences).

Sensory stimulation. Facial whisker stimulation was delivered by Pressure System IIe (Toohey Co.) as $40 \mathrm{~ms}$ pulses at $20-40$ psi. Dendrites were scored as responding based on all sensory trials if the number of events detected in two movie frames (or 10 letterbox scans) immediately after a stimulus exceeded a baseline rate determined from the seven frames (or 100 letterbox scans) preceding the stimulus, as determined by a $\chi^{2}$ test $(2 \mathrm{df} ; p<0.05)$. The response probability was defined as $p_{r}=$ $\left(N_{\text {resp }}-N_{\text {prestim }}\right) /\left(N_{\text {total }}-N_{\text {prestim }}\right)$, where $N_{\text {resp }}$ is the number of trials in which an event occurred in the response period, $N_{\text {prestim }}$ is the number of trials in which an event occurred in a prestimulus period of equal duration, and $N_{\text {total }}$ is the total number of trials. The number of dendrites responding at once was calculated from two frames in movie scans and one frame in letterbox scans.

Sensory decoding rule. A train of PC events at times $t_{i}$ was assumed to trigger an enhancement process with time course $F(t)=1+$ $A \sum_{i} \mathrm{H}\left(t-t_{i}\right) \exp \left[\left(t_{i}-t\right) / \tau\right]$, where $\mathrm{H}$ is the Heaviside step function, $A=3$, and $\tau=140 \mathrm{~ms}$. For each time point $t_{j}$ in which at least one PC event occurred, neurotransmitter release $\mathrm{R}$ was defined as the sum of $F\left(t_{j}\right)$ over all active PCs and converted to a postsynaptic response using the sigmoidal relationship $O\left(t_{j}\right)=1 /\left[1+\exp \left(R_{0}-R\left(t_{j}\right) / \rho\right)\right.$, where $R_{0}$ ranged from 0.5 to $2 N$, and $\rho$ ranged from 0.1 to $1 N$, where $N$ was the total number of dendrites. $R_{0}$ and $\rho$ were varied to optimize the receiver operating characteristic curve (ROC) by minimizing the distance between the left top corner [point $(0,1)]$ and ROC curve. The decoder output was taken as the sum of all $O\left(t_{j}\right)$ in the $512 \mathrm{~ms}$ after the sensory stimulus.

Averages are given as mean \pm SD unless otherwise noted.

\section{Results}

Identification of individual dendrites and characterization of calcium transients

We used in vivo two-photon microscopy (Fig. $1 A$ ) to monitor spontaneous and sensory-evoked PC complex spikes in mouse and rat crus II, a cerebellar region that receives peri-oral and other somatotopic sensory information (Brown and Bower, 2001). We bulk loaded the molecular layer of the intact cere- 
bellum with the fluorescent indicator dye Oregon Green BAPTA-1/AM (Sullivan et al., 2005).

This preparation allowed us to record calcium transients optically $90-120 \mu \mathrm{m}$ above the PC body layer in fields of view up to $270 \mu \mathrm{m}$ wide, in which, under anesthesia, the observed calcium signals come mainly from PC dendritic arbors (Sullivan et al., 2005). PC dendritic arbors are finely branched and fill a flat, fan-like, parasagittally oriented space $\sim 200 \mu \mathrm{m}$ wide and 6-10 $\mu \mathrm{m}$ thick (Palay and Chan-Palay, 1974). In mice and rats, arbors appear in transverse sections as uninterrupted tube-like structures (Johnston, 2005) separated by $4-8 \mu \mathrm{m}$ from the nearest neighbor with minimal intermingling. The nonoverlapping arrangement of $\mathrm{PC}$ arbors is visible in transgenic mice expressing green fluorescent protein (GFP) under the PC-specific L7 promoter (Fig. 1A).

Anatomical separation of dendritic arbors made it possible for pixels from calcium imaging experiments to be assigned to specific PCs. Because bulk loading with Oregon Green-1/AM (Fig. $1 B$ ) gave lower contrast than GFP, pixels were classified using correlations in the pixel time courses (Ozden et al., 2008) that arose from CF-evoked dendritic action potentials, which trigger calcium entry throughout the PC dendritic arbor (Ross and Werman, 1987; Tank et al., 1988). Between 15 and 40 neighboring PC arbors were visible per field of view.

PC dendritic arbors generated calcium transients at $0.2-1 \mathrm{~Hz}$, as expected from observed rates of CF firing (Brown and Bower, 2001). Line scans ( $2 \mathrm{~ms} /$ line) (Fig. $1 A$, bottom, green trace) across dendrites showed that calcium transients, which span the arbor, rose in $\sim 10 \mathrm{~ms}$ and fell with a half-maximal decay time of $170 \pm 50 \mathrm{~ms}$ and an exponential decay time constant of $280 \pm 60$ ms (mean \pm SD, 29 dendrites in 4 experiments), consistent with previous reports in vivo (Sullivan et al., 2005). These slow decay times and the low rate of calcium transients $(0.48 \pm 0.15 \mathrm{~Hz})$ made it possible to detect individual events even at frame acquisition times as long as $256 \mathrm{~ms}$.

In movies with low frame rates (128 and $256 \mathrm{~ms} /$ frame), the orientation of the scan pattern was adjusted to align dendritic arbors in the direction of fast scanning, thus establishing a precise within-frame time at which each dendritic arbor was scanned. Because transients might not be detected until the following frame, event times were adjusted using a likelihood-based correction (Ozden et al., 2008). For line scans and letterbox (10-line frame) scans, the line scan direction was set perpendicular to the dendrite orientation to allow many dendrites to be monitored at once.

\section{Calcium transients in Purkinje cell dendrites track complex spikes}

To confirm the complex spike origin of transients, simultaneous optical and electrophysiological recordings were performed (Fig. $1 \mathrm{~A}$, green and black traces, respectively). Fluorescence transients in a dendritic arbor were almost always associated with complex spikes recorded near the originating cell body. Fluorescence transient events identified by a template matching-andthresholding algorithm (Ozden et al., 2008) (supplemental Movies 1, 2, available at www.jneurosci.org as supplemental material) were associated with $95.4 \pm 3.0 \%$ of electrophysiologically recorded complex spikes (mean $\pm S D, 16$ recordings in 5 rats, 850 complex spikes). Conversely, $92.2 \pm 5.1 \%$ of detected transients ( 835 transients) were accompanied by a complex spike in the associated electrophysiological recording. Thus, in vivo imaging of PC dendritic calcium transients is a reliable means of monitoring complex spike activity.

\section{Nearby Purkinje cells have highly correlated activity}

Climbing fibers originate from inferior olivary neurons, which are electrically coupled to one another (Llinás et al., 1974; Devor and Yarom, 2002) and frequently generate simultaneous action potentials (Devor and Yarom, 2002), suggesting that PC complex spike firing should manifest a high degree of synchrony. In populations of PCs, we found that nearby arbors often fired at the same time (Fig. 1B,C).

The rapid rise time of calcium transients allowed complex spike times to be determined with a precision of a few milliseconds. Line scans $(2 \mathrm{~ms} /$ line $)$ showed that calcium transients in multiple arbors often began at the same time (Fig. $1 B$ ), even in arbors that were separated mediolaterally and thus would not be expected to receive input from the same CF (Sugihara et al., 1999, 2001). Arbor-arbor cross-correlations (Fig. 1C, left) were highest at a relative timing of $4 \mathrm{~ms}$ or less in 190 of 213 pairs of dendrites (Fig. $1 C$, right) $(n=8,4$ rats and 4 mice). In these experiments, which spanned $9 \pm 2$ dendritic arbors per field of view, $90 \%$ of all calcium events were associated with events in at least one other PC. Thus, PC complex spike firing almost always occurs in groups, presumably driven by the activity of multiple olivary neurons (Wylie et al., 1995).

Previous measurements done with electrodes spaced hundreds of micrometers apart (Welsh et al., 1995) suggested that PC-PC correlations were low, typically no more than 0.2 . In our recordings, which sampled every PC in a field of view, we observed much higher arbor-arbor event time cross-correlations (maximum correlation, 0.88; interquartile range, 0.12-0.42) (Fig. 1D). The highest correlations corresponded to pairs of arbors closely spaced in the mediolateral and parasagittal (Fig. $1 D$ ) directions. These correlations were considerably larger than reported previously (Welsh et al., 1995) (indicated by arrowheads in Fig. $1 D$ ) and consistent with measurements from pairs of neurons separated by tens of micrometers (Bell and Kawasaki, 1972). Thus, complex spike coactivation is strongest on a local scale, $<100 \mu \mathrm{m}$.

We tested for several potential errors of interpretation. On average, the size of cross-correlations was not affected by the rate of scanning, a risk for frame rates comparable with or lower than the event rate (supplemental Fig. $1 \mathrm{~A}$, available at www.jneurosci.org as supplemental material). We also tested the extent to which high correlations could be ascribed to misidentification of dendritic arbor boundaries. Such misidentification could lead to mixing of signals between pairs of neighboring arbors. We compared the cross-correlation of fluorescence signals from outer one-thirds of arbors with one another and with parasagittally neighboring arbors from different PCs. The average correlation between the end of an arbor and the closest neighbor of that arbor was $0.28 \pm 0.13$, much smaller than the correlation between opposite ends of the same arbor $(0.78 \pm 0.09$; $p<$ $0.01, t$ test) (supplemental Fig. $1 B$, available at www.jneurosci. org as supplemental material). We also tested whether the end of an arbor showed detectable calcium transients when its closest neighbor fired but its own parent arbor did not. In this case, the peak fluorescence change was $3 \pm 12 \%$ the size of the full signal seen when its own arbor fired (supplemental Fig. 1C, available at www.jneurosci.org as supplemental material), a level that did not lead to any falsely detected events in the arbor end. Together, our analysis indicates that correlations in our frame scan movies measure the true amount of synchrony and that crosstalk between neighboring dendritic arbors emanating from different PCs is low. 
A

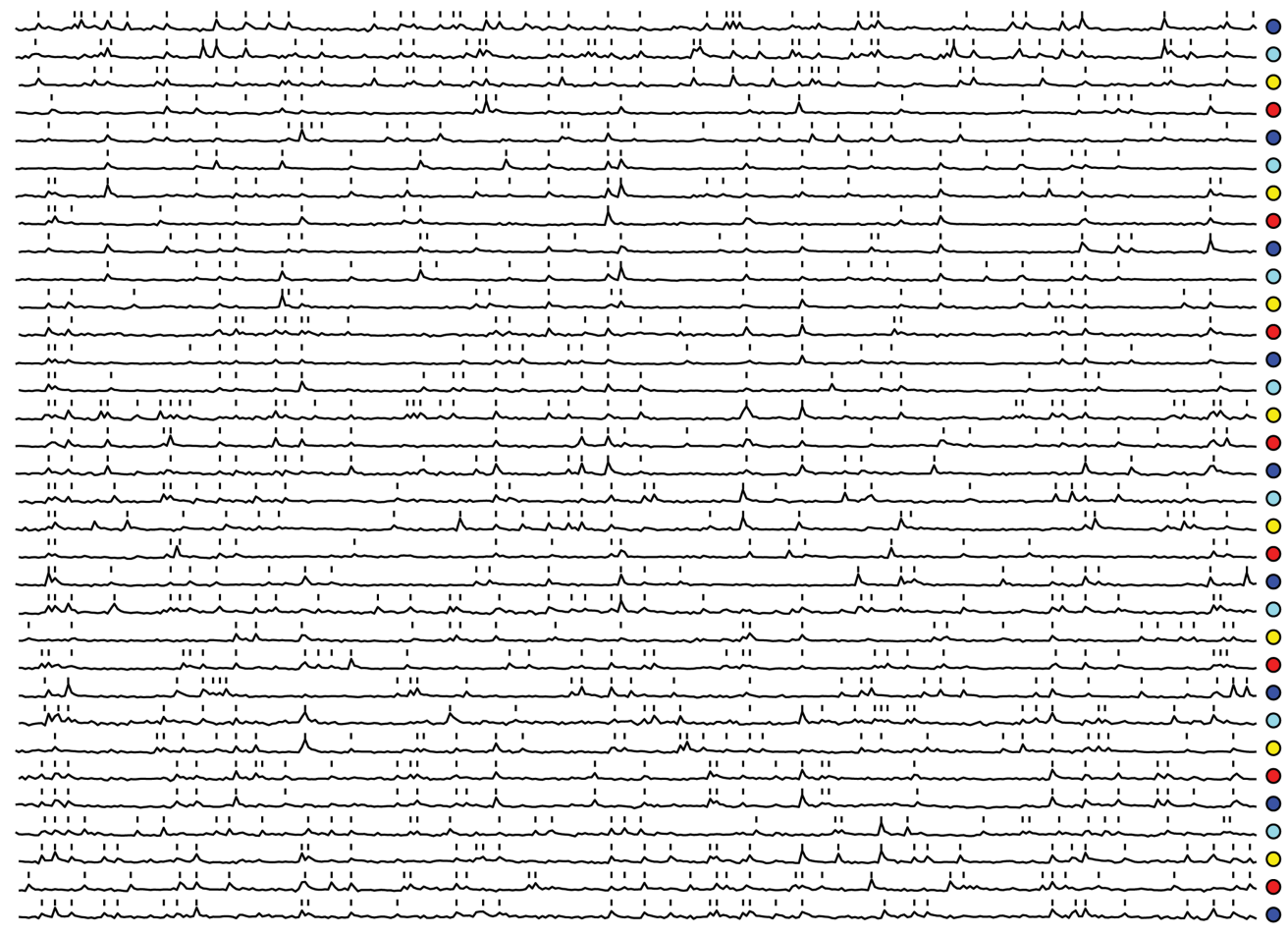

$10 \mathrm{~s}$

B

\section{Dendrites}

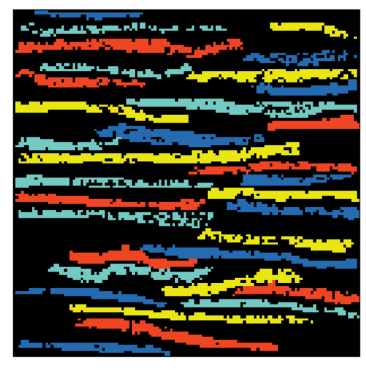

$30 \mu \mathrm{m}$
C

\section{Correlation matrix}

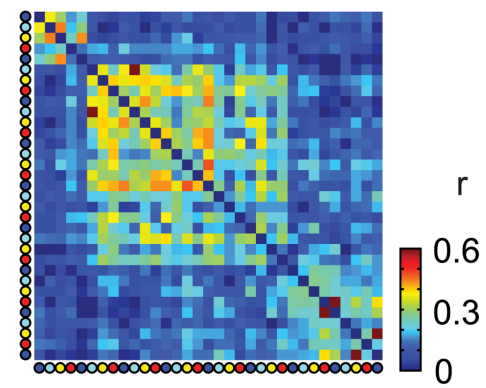

D

\section{Microbands}

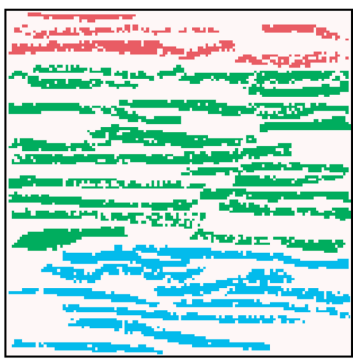

$30 \mu \mathrm{m}$

Figure 2. Organization of Purkinje cell complex spikes into synchronously active microbands. $A$, Example events (black ticks) from 33 dendritic arbors in a single movie. Arbor identity is indicated by the colored circles and carried over into $B$ and $C . B$, Locations of identified dendrites. $C$, Arbor-arbor correlations of event times. Diagonal values of 1 are shown as black. $\boldsymbol{D}$, Microbands of coactive arbors were identified using the meta-k-means algorithm and shown in different colors.

Purkinje cell correlations are strongest in the parasagittal direction

We found that correlations were strongest at distances of tens of micrometers, declining steeply in the mediolateral direction (Fig. $1 D$, left) with a characteristic half-maximal distance of $29 \pm 13$ $\mu \mathrm{m}$ ( 11 fields of view in three mice and three rats; for rats, $30 \pm 18$ $\mu \mathrm{m}$ and for mice, $29 \pm 11 \mu \mathrm{m})$. Correlations dropped more gradually in the parasagittal direction (Fig. $1 D$, right). Using the centers of visible dendrites as the PC location, half-maximal correlations were reached at a distance of $102 \pm 21 \mu \mathrm{m}$ (50 dendrite pairs in three mice), which is an underestimate of the true distance because in many cases only part of a dendritic arbor was visible. Correlations among dendrites showed an overall preference for the parasagittal direction (parasagittal half-maximal dis- tance greater than mediolateral half-maximal distance; $p<0.01$, two-tailed test). In summary, synchronized firing of PCs is organized predominantly parasagittally with the strongest correlations occurring on a scale of tens of micrometers, a distance essentially unexplored in previous physiological reports.

\section{Purkinje cell coactivation occurs in sagittally oriented microbands}

Despite the overall strength of short-distance correlations, correlations between immediately adjacent pairs of PC dendritic arbors ranged from 0.08 to 0.83 . This wide range of correlations suggested that pairwise coupling was not smoothly varying but instead organized to form discrete groups. To test this idea, recordings were made from up to 40 dendritic arbors at once (Fig. 
A

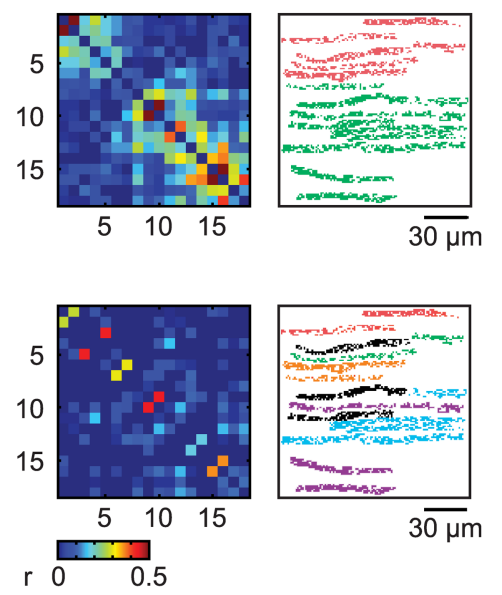

B

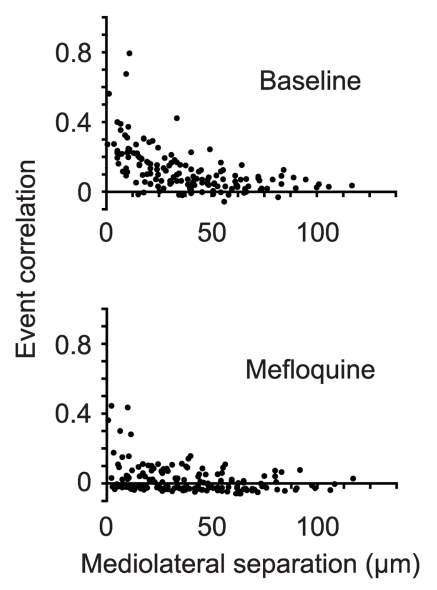

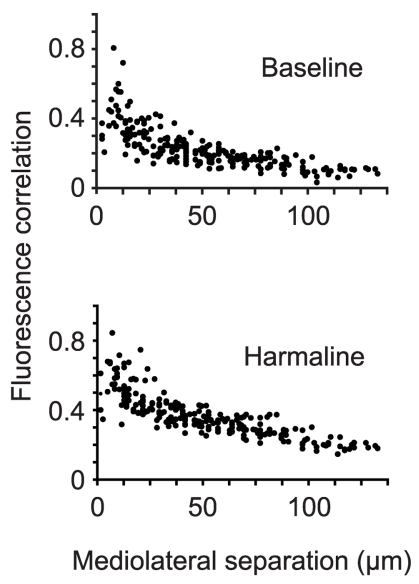

C
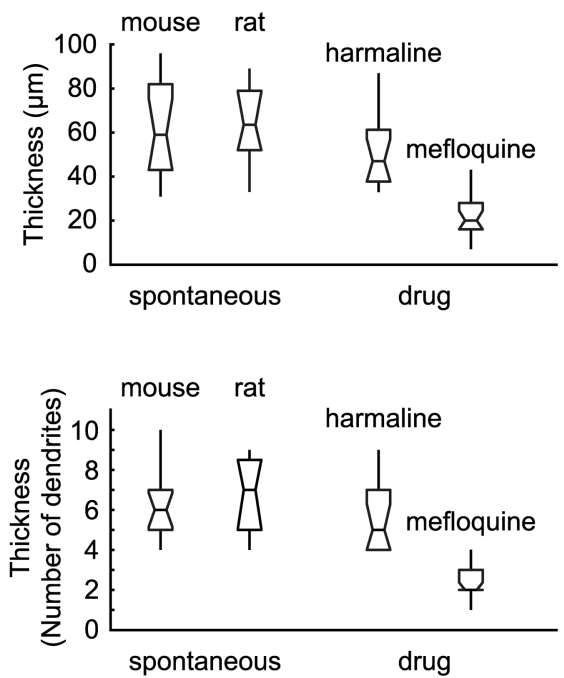

D

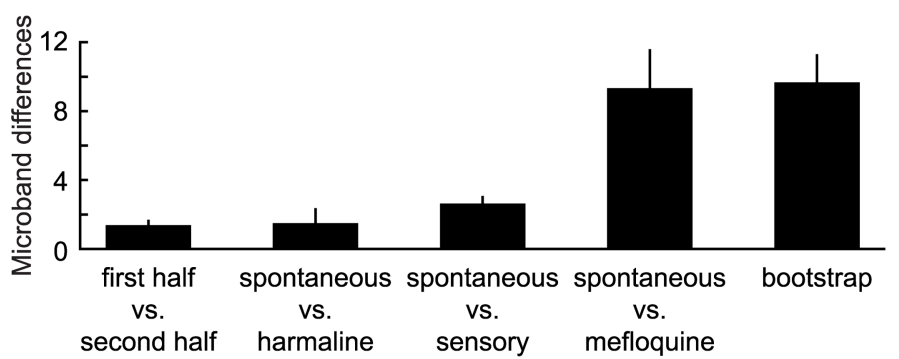

Figure 3. Microband stability and mechanism of generation. $\boldsymbol{A}$, Arbor-arbor correlations, locations of arbors color-coded by microband membership, and correlations plotted as a function of mediolateral separation distance, analyzed from spontaneous activity before (top) and 30 min after (bottom) infusion of mefloquine into the inferior olive. In the middle bottom, the black regions denote arbors that did not cluster with any other arbor using meta-k-means. $\boldsymbol{B}$, The same type of data from another experiment, taken before (top) and $15 \mathrm{~min}$ after (bottom) injection of harmaline. C, Box plots (minimum, interquartile, median, and maximum values) of mediolateral thickness of all microbands during spontaneous activity before and after drug treatment. $\boldsymbol{D}$, Differences in microbands between various conditions. Differences were defined as the number of arbors needed to change membership to go from one microband structure to another. "Bootstrap" refers to comparisons between two different experiments each containing the same numbers of arbors and microbands. Error bars are SEM.

$2 A, B$ ). In these recordings, plots of all pairwise correlations (Fig. $2 C$ ) revealed an emergent pattern in which groups of neighboring dendritic arbors often fired at the same time but were less correlated with nearby groups.

We identified groups computationally using meta- $k$-means (Ozden et al., 2008), a robust clustering procedure based on repeated runs of the $k$-means algorithm (D'haeseleer, 2005). $k$-means is used widely to find structure in gene expression datasets when the number of clusters is known in advance. Meta- $k$-means addresses the absence of a priori information on the number of clusters by aggregating many runs of $k$-means to determine the number and composition of clusters. This approach is robust, versatile, and produces consistent results when applied to calcium imaging datasets (Ozden et al., 2008). We applied meta- $k$-means to matrices of likelihoodcorrected event times recorded from all dendrites. We defined a distance metric based on dendrite-dendrite correlation, so that identical event sequences are separated by zero distance.
Use of this "pattern distance" metric identifies clusters in which coactivation is high within groups and low between groups.

Identified groups (Fig. 2D) took the form of microbands that extended across the field of view parasagittally. Microbands included 3-19 arbors that were near one another, usually in a contiguous region, and spanned 3-11 arbors in the mediolateral direction. To quantify the degree to microbands were distinct entities, we found that the mean correlation in pairs of arbors within a microband $(0.25 \pm 0.12,266$ pairs, 35 microbands in 10 mice) was higher than the mean dendrite-dendrite correlation in pairs of neighbors across microband borders $(0.17 \pm 0.08,22$ pairs; $p<0.01)$.

In cases in which both boundaries of a band were visible, the microband spanned $6.3 \pm 2.0$ dendritic arbors mediolaterally in mice ( 15 fields of view, 10 animals) and $6.8 \pm 1.9$ dendritic arbors in rats (nine fields of view, four animals). The thickness of microbands was also similar between mice $(61 \pm 23 \mu \mathrm{m})$ and rats $(64 \pm$ 
A
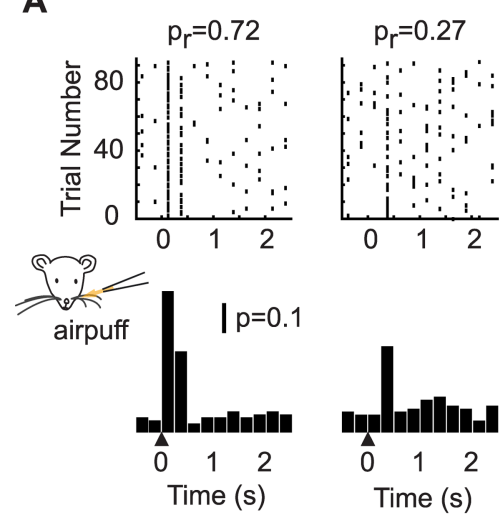

^ airpuff onset
B
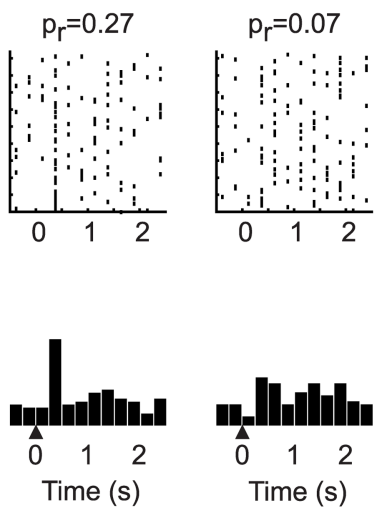

C
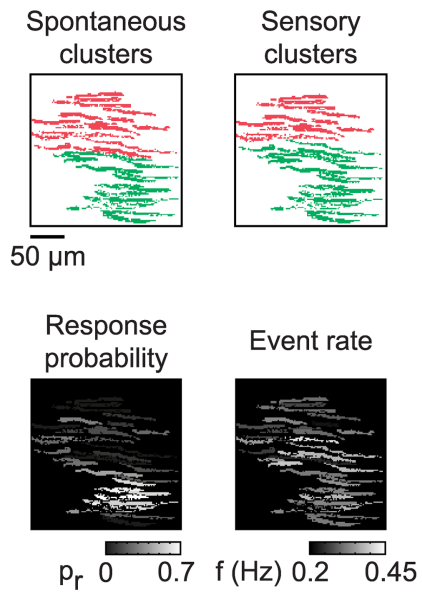

D

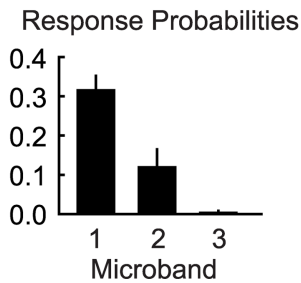

E

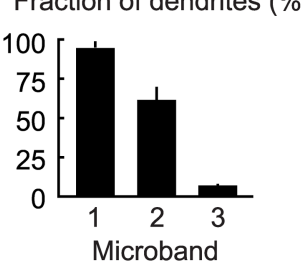

Figure 4. Microband organization of sensory responses. $A$, Responses to 100 air puffs for dendritic arbors with high response probability $\left(p_{r}=0.72\right)$, medium probability ( $\left.p_{r}=0.27\right)$, and low probability ( $p_{r}=0.07$ ), plotted as event rasters (top) and histograms (bottom). $\boldsymbol{B}$, Microbands determined from the same field of view for spontaneous activity (left) and sensory-evoked activity (right). C, The probabilities of air-puff-evoked responses (left) and the spontaneous event rate (right). $\boldsymbol{D}$, Average response probabilities for the highest-responding microband in a field of view (band 1), the adjacent band (band 2), and the next-most adjacent band (band 3). $\boldsymbol{E}$, The fraction of arbors responding within the same three band categories as in $\boldsymbol{D}$. Error bars indicate SEM.

$19 \mu \mathrm{m})$. In summary, olivocerebellar projections show local modular coupling structure on a scale of $<100 \mu \mathrm{m}$ as measured in the molecular layer.

\section{Purkinje cell coactivation depends on gap junctional coupling in the inferior olive}

Microband identity might be determined by the strength and pattern of electrical coupling among olivary neurons. We therefore examined how microbands were altered by pharmacological manipulation of the inferior olive. Infusion into the inferior olive of mefloquine, which blocks the gap junction channels connexin-36 and connexin-50 (Cruikshank et al., 2004) to decouple olivary neurons (Urbano et al., 2007), reduced correlations within microbands from $0.23 \pm 0.09$ to $0.08 \pm 0.07$ (Fig. $3 A$, left $)(n=49$ dendrites in 3 mice; mefloquine smaller than predrug, $p<0.01$, paired $t$ test) and modestly reduced the mean frequency of dendritic calcium transients from $0.33 \pm 0.07$ to $0.19 \pm 0.07$ events per second per dendrite $(n=49$ dendrites; $p<$ $0.01)$. Microband structure was also disrupted, leaving only lone uncorrelated dendrites and pairs of correlated dendrites (Fig. 3A, bottom left).

Mefloquine has additional effects at high concentrations on voltage-gated conductances (Cruikshank et al., 2004). However, harmaline, which also interferes with olivary signaling by modulation of intrinsic neuronal conductances (de Montigny and Lamarre, 1973), did not strongly affect clustering patterns (Fig. $3 B, C)$ or the distance dependence of dendrite-dendrite fluorescence correlations (Fig. $3 B$, right), although correlations were increased from $0.26 \pm 0.10$ to $0.44 \pm 0.15(n=116$ dendrites in 2 mice and 3 rats; $p<0.01$ by paired $t$ test), and the electrophysiologically recorded complex spike rate increased from $0.84 \pm$ 0.56 to $2.03 \pm 0.56 \mathrm{~Hz}(n=3$ in 1 mouse and 2 rats; $p<0.05$ by paired $t$ test). Harmaline observations were confirmed in scans done at higher sampling rates (data not shown). These results indicate that the organization of microbands specifically requires electrical coupling in the inferior olive.

To test whether coupling-dependent microband membership was stable over time, microbands were compared from $5 \mathrm{~min}$ periods comprising the first and second halves of recordings $(n=$ 16 fields of view from 10 mice and 4 rats). Between the halves, microbands were nearly unchanged, with only $5 \%$ (22 of 477) of dendrites changing their assigned membership (Fig. 3D). Membership-changing dendrites were usually found at boundaries between microbands and were comparable in number with those changing membership after harmaline injection but far fewer in number than seen under mefloquine or when cluster structures were compared from unrelated experiments to provide a bootstrap measure of the maximum possible change (Fig. 3D) ( $p<0.01$, all four pairwise comparisons, one-tailed test). Thus, microband membership was stable for the duration of recordings and during consecutive recordings from the same field of view (range of inter-movie intervals, 6-113 $\mathrm{min}$ ).

\section{Sensory response coactivation patterns maintain} microband boundaries

The existence of strong, clustered electrical coupling in the inferior olive suggested that sensory-driven complex spike responses could be synchronized across PCs within a microband. To test this idea, PC dendrites were monitored under delivery of air-puff stimuli to the ipsilateral whisker pad. On each trial, air puffs triggered responses in some but not all dendrites in a field of view, with different dendrites responding from trial to trial (Fig. 4A). Consistent with previous mapping studies (Brown and Bower, 2001), dendrites fired within the first two full scan frames (512 $\mathrm{ms}$ ) or 25 box scans $(500 \mathrm{~ms})$ after presentation of the air puff with response probabilities ranging from 7 to $72 \%$ (29 $\pm 15 \%$, 150 of 195 dendrites in eight mice, eight fields of view) (Fig. 4A).

Application of clustering analysis to sensory response data revealed a microband structure that was almost identical to that measured under spontaneous conditions during the same experiment (Fig. 4B). Nearly all dendrites showed the same membership between spontaneous and sensory conditions. Only $10 \%$ of dendrites (15 of 153 dendrites in 12 microbands, five full-scan fields of view in five mice) changed membership, usually at the boundaries between bands. The sensory response probability $p_{r}$ was not correlated with mediolateral position within a microband (absolute value of rank correlation of $0.31 \pm 0.19,12$ microbands of 6-20 dendrites; correlations not significant by two-tailed test with correction for multiple comparisons), suggesting that olivocerebellar sensory input was not mapped more finely than the microband level. Responding dendrites were, however, distributed heterogeneously between microbands 
A

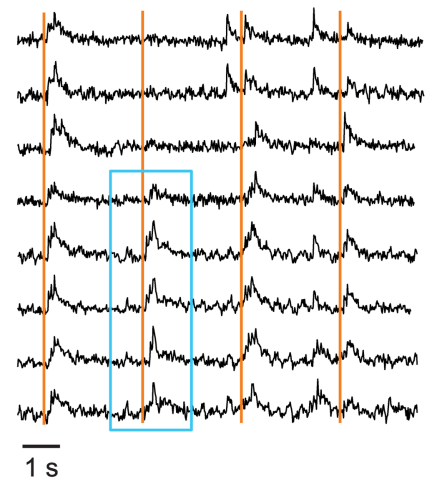

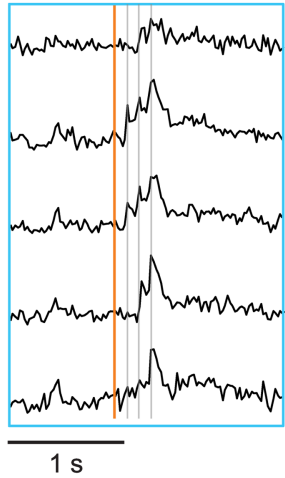

$1 \mathrm{~s}$
B

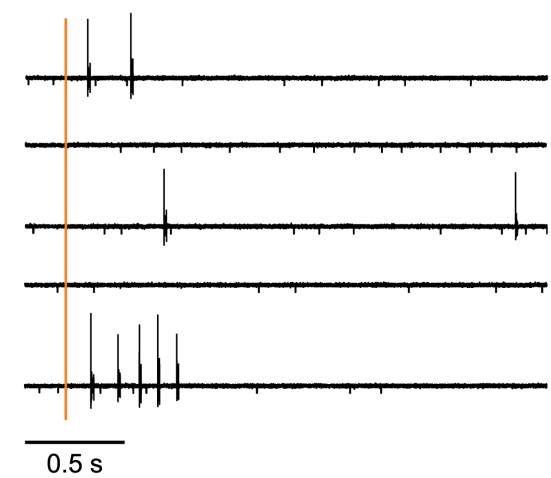

Peristimulus time histogram

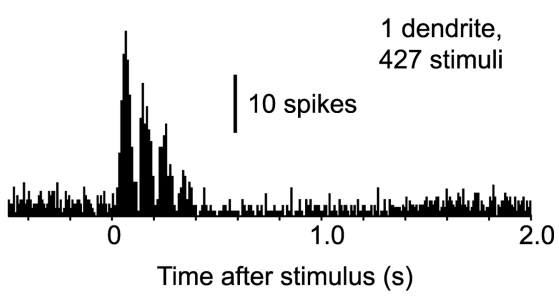

C

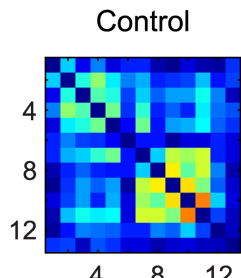

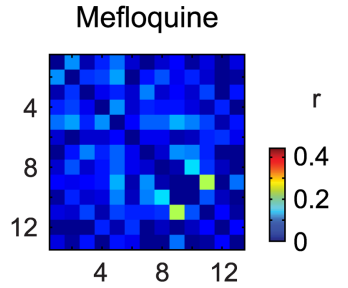

D

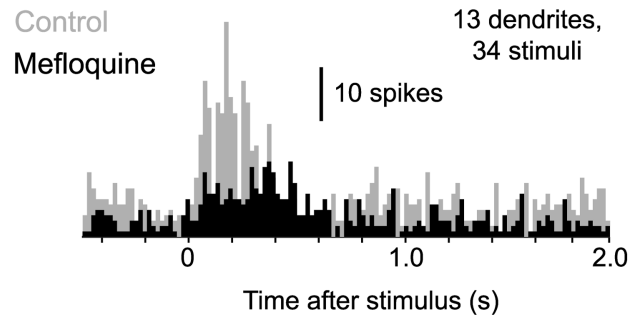

Figure 5. Coactivated bursts in sensory-evoked calcium transients across a population of Purkinje cells. $A$, Data from eight adjacent dendritic arbors. The vertical orange lines indicate times of air puffs. Responses show bursts of multiple events separated by $\sim 100$ ms that are synchronized across the population of dendrites (see blue outlined region, enlarged in inset, right). A peristimulus histogram of all calcium transients in all 20 dendrites is shown at the bottom. $\boldsymbol{B}$, Example complex spike responses from a single-unit extracellular recording after repeated presentation of an air puff (vertical orange line). The simple spikes were removed digitally for better visualization. Peristimulus time histogram of responses to all 427 air puffs is shown at the bottom. C, Correlation matrices of dendritic activity before (left) and after (right) mefloquine injection into the inferior olive. Stimuli were presented every 3 s. D, Peristimulus time histograms before and after mefloquine injection corresponding to the movies whose correlation matrices are shown in $\boldsymbol{C}$.

within a field of view (Fig. $4 C-E$ ), with $77 \pm 13 \%$ of the variance in $p_{r}$ accounted for by cluster membership $(n=5)$ (Fig. $4 D$ ). Compared with the microband with the highest overall average $p_{r}$ $(0.32 \pm 0.04$, mean $\pm \mathrm{SEM} ; n=5)$, the nearest microband had a significantly higher average $p_{r}$ than the next one out $(0.12 \pm 0.05$ vs $0.01 \pm 0.01$, mean $\pm \mathrm{SEM} ; n=5 ; p<0.01$, one-tailed test) (Fig. $4 D$ ), indicating that responsiveness to the stimulus tended to vary in a gradient across multiple microbands.

\section{Sensory stimuli trigger repeated synchronous bursts}

Air-puff stimulation triggered responses in an average of $8.8 \pm$ 4.7 dendrites of $32.8 \pm 5.0$ dendrites at once in a field of view $(457$ trials in five mice) compared with an average of $2.9 \pm 3.5$ dendrites responding at once spontaneously (5112 events; different from air-puff-evoked stimulation; $p<0.01)$. Because of the low time resolution of movies ( $256 \mathrm{~ms} /$ frame), these measurements may have combined asynchronous responses or, conversely, assigned synchronous events to different frames (Ozden et al., 2008). It was, therefore, necessary to scan dendrites at higher time resolution. We scanned smaller fields of view, containing 10-20 dendrites, at high speed ( $20 \mathrm{~ms} /$ frame; $n=3$ mice, 184 stimuli) (Fig. 5A). In these experiments, air puffs triggered responses in $4.9 \pm 1.8$ dendrites $(35 \pm 2 \%$ of the total $)$ at once compared with $1.5 \pm 0.2$ dendrites $(11 \pm 3 \%)$ during spontaneous activity (1209 events; numbers and percentages of dendrites both different by one-tailed test, $p<0.05 ; n=3)$. Therefore, information about the occurrence of a sensory stimulus was conveyed in part by the number of synchronously responding dendrites.

Fast scanning also revealed that sensory responses were characterized by repeated firing during each response. Air puffs evoked multiple calcium transient events in single dendrites, each of which was also synchronized across dendrites (Fig. 5A, top). Within each burst of events, synchronous events could occur in some or all responding dendrites at once (Fig. 5A, top, inset). The overall response pattern was a burst of two to five transients occurring at a frequency of $\sim 10 \mathrm{~Hz}$ (Fig. $5 \mathrm{~A}$, bottom), with the first event occurring within $40-100 \mathrm{~ms}$ of the stimulus.

Bursts contained $2.94 \pm 0.77$ events ( $n=365$ bursts) during air-puff stimulation, in contrast with spontaneous activity, in which multiple firing at $100 \mathrm{~ms}$ intervals was essentially absent 
A

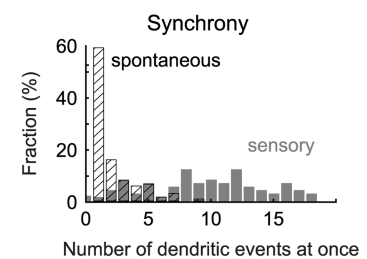

D

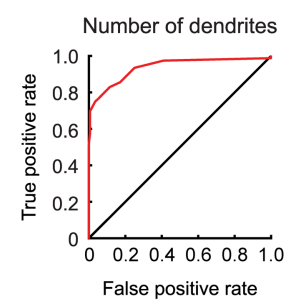

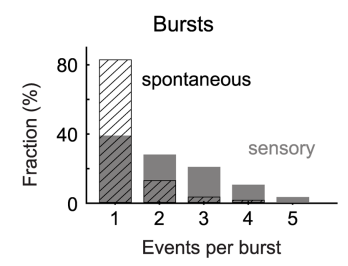

$E$

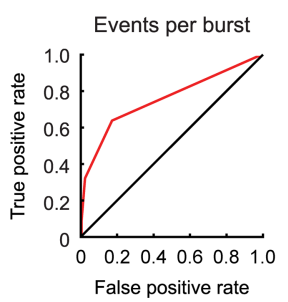

C

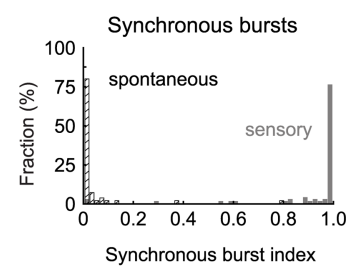

$\mathbf{F}$

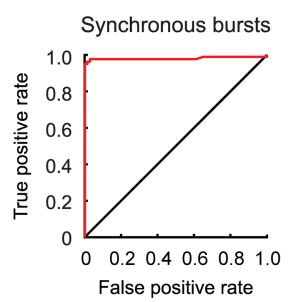

Figure 6. Characterization of sensory-evoked population responses. A, Histogram of the number of dendritic arbors active within two-frame time windows from a mouse experiment in which 20 dendrites were scanned at $20 \mathrm{~ms}$ resolution. The hatched bars represent spontaneous activity, and the black bars indicate sensory responses. $\boldsymbol{B}$, Histogram of the number of calcium transients per burst for spontaneous and sensory-evoked activity. $C$, Histogram of the output of a model combining the information from coactivation and bursts. $\boldsymbol{D}-\boldsymbol{F}$, Receiver operating characteristic curves constructed from cumulative histograms of the data in $A-C$, respectively.

$(1.17 \pm 0.46$ transients per response; $n=1017$ events; different from air-puff stimulation, $p<0.05)$. Extracellular microelectrode recordings from single PCs (Fig. $5 B$ ) confirmed that airpuff stimuli could trigger complex spikes separated by $\sim 100 \mathrm{~ms}$ $(n=4$ mice). The timing of complex spikes was similar from trial to trial, consistent with the synchrony among PCs observed in imaging experiments.

To test whether stimulus-evoked synchrony relied on electrical coupling, we imaged sensory responses before and after injecting mefloquine into the inferior olive. Pairwise correlations among all responding dendritic arbors were $0.15 \pm 0.06$ before injection and $0.03 \pm 0.04$ after injection (Fig. $5 C)(n=156$ pairs of arbors in 2 mice; mefloquine smaller than predrug, $p<0.01$, paired $t$ test). The discrete $10 \mathrm{~Hz}$ repetitive nature of sensory responses was replaced by a continuous period of enhanced probability of calcium transients (Fig. 5D). These observations indicate that sensory-evoked excitatory input to the inferior olive is converted by a gap junction-dependent mechanism to synchronous output firing.

\section{The occurrence of sensory events can be decoded from ensemble activity}

To quantify how multidendrite complex spike firing and bursting in PC ensembles might distinguish stimuli from spontaneous activity, we plotted the distributions (Fig. $6 A, B$ ) of activity parameters (the number of dendritic arbors responding and the number of calcium transients per response) during sensory-evoked activity. In addition, plots of cumulative true positives versus cumulative false positives, starting from the highest values of the parameters, defined ROCs (Fig. 6D,E). An ROC based solely on the number of simultaneously active dendrites (Fig. 6D) indicated an optimum accuracy in which $69 \pm 13 \%$ of stimuli were detected with a false-positive rate of $17 \pm$ $5 \%$. Analysis of burst length alone gave a similar optimum accuracy of $64 \pm 4 \%$, with a false-positive rate of $14 \pm 3 \%$ (Fig. $6 E$ ). Therefore, both bursting and synchrony carry information about the occurrence of a sensory event.

To quantify the degree to which stimuli were encoded in activity patterns, we designed a two-stage decoder (for details, see
Materials and Methods). In the first stage, any spike in a PC enhanced the effect of subsequent spikes occurring in the same $\mathrm{PC}$ with a decaying time constant. In the second stage, the resulting responses from all PCs were summed through a sigmoidal input-output function (Fig. $6 C)$. The resulting output had an ROC (Fig. $6 F$ ) that rejected $95-98 \%$ of spontaneously occurring events. In three fields of view containing 10,12 , and 20 dendrites, the decoding rule detected $87 \pm 10 \%$ of air puffs. The highest accuracy (98\%) and lowest false-positive rate $(2 \%)$ occurred for the 20-dendrite case, suggesting that discrimination was limited by the number of dendrites monitored. Thus, eventrelated information is present in the ensemble activity patterns of PC dendrites.

\section{Discussion}

Our findings show that PCs are coactivated in microbands of many neighboring dendritic arbors at once. Correlations among PCs in microbands were high enough to accurately represent single events. Correlations were similar in amplitude and structure when measured with line scans and frame scans, indicative of synchrony on the timescale of at most a few milliseconds, and were sensitive to gap junction blockers. Our measurements furthermore show that complex spike activity is organized into microbands with a characteristic thickness of $30-100 \mu \mathrm{m}$. This distance provides a scale for the microzonal organization of the cerebellum.

Previous studies using anatomical tracing (Groenewegen et al., 1979; Sugihara et al., 2001; Pijpers et al., 2005), antigen staining (Herrup and Kuemerle, 1997; Sugihara and Shinoda, 2007), electrophysiological recording (Bell and Kawasaki, 1972; Sasaki et al., 1989), and low-resolution imaging (Chen et al., 1996; Dunbar et al., 2004) revealed a parasagittal organization of CF projections into bands several hundred micrometers thick (Oscarsson, 1979; Chen et al., 1996). We do not know at present whether microband boundaries, which are more closely spaced, coincide with one or more of the previously found types of boundary. Reconciling these various observations of zonation will require additional investigation.

Microbands of PCs comprise one component of a three-part system connecting Purkinje cells, the inferior olive, and the deep nuclei (Apps and Garwicz, 2005; Sugihara and Shinoda, 2007). The olivonuclear projection links well defined subregions of the olive to counterparts in the deep nuclei, which in turn send a reciprocal connection back to the inferior olive (Voogd and Glickstein, 1998). Each olivonuclear axon gives rise to multiple CFs that innervate a parasagittal "microzone" of PCs (Oscarsson, 1979). The organization of the projection from synchronized olivary neurons to the cerebellar cortex would account for the local correlations that we have observed. Also, because calcium transients in PCs closely reflect activity in olivary neurons, the activity patterns we observe are also transmitted as direct excitation to neurons of the cerebellar nuclei via the olivonuclear pathway.

Thus, olivary neurons can influence the deep cerebellar nuclei in two ways: by indirect disynaptic inhibition via PCs and by direct excitatory synaptic connections. This circuit arrangement provides several means by which olivary synchrony could be pro- 
cessed in the cerebellar cortex and nuclei. First, synchronous complex spiking might trigger powerful inhibitory responses in nuclear cells. Each olivary axon distributes $\sim 10$ CFs arranged parasagittally across multiple folia (Hrycyshyn et al., 1989; Sugihara et al., 1999). Therefore, an observed microband of 3-19 dendrites is likely to represent as many as several hundred additional simultaneously firing PCs outside the field of view. Each PC axon in turn projects to dozens of deep nuclear neurons (Palkovits et al., 1977), and PCs outnumber deep nuclear neurons by 20-fold (Caddy and Biscoe, 1979; Gould and Rakic, 1981; Alvarez-Otero et al., 1996). Thus, a deep nuclear neuron may receive input from up to several hundred PCs. Consistent with this hypothesis, olivary activation has been shown to trigger large IPSPs in deep nuclear neurons as in vivo by whole-cell recording (H. Jörntell, personal communication).

Microbands of simultaneously active PCs may have additional effects beyond simple inhibition. Each complex spike is followed by a pause in simple spiking that lasts tens of milliseconds, thus briefly vetoing the influence of the mossy fiber/granule cell pathway (Steuber et al., 2007). The pause is often followed by a depolarizing rebound (Molineux et al., 2008); in addition, a second depolarizing effect arises from direct monosynaptic excitation (Llinás and Mühlethaler, 1988) because each olivary neuron projects directly to the deep nuclei (Voogd and Glickstein, 1998; Apps and Garwicz, 2005). Thus, synchrony among olivary neurons may act through several routes to evoke a strong and stereotyped effect on nuclear neurons that mixes inhibition, excitation, and silencing or modulation of simple spikes.

In addition to providing a way of distinguishing stimulusevoked complex spike events from spontaneous firing, synchrony also provides a way of combining unreliable single-PC responses to make a more reliable ensemble response. In addition, meaning may be conveyed by the specific combinations in which PCs fire, either within or across microbands.

In awake animals, synchrony is a prominent feature of complex spike-based signaling. Lang et al. (1999) reported that awake animals show slightly lower complex spike firing rates but similar distance-dependent correlations compared with ketamine/xylazine anesthesia. However, ketamine/xylazine anesthesia has also been reported to depress evoked climbing fiber responses as monitored by field potential recording in decerebrated rats (Bengtsson and Jörntell, 2007). It remains to be determined how synchrony will be manifested on short-distance scales under awake conditions.

Awake patterns of PC activation are potentially more complex than the anesthetized case. Under anesthesia, sensoryevoked microbands follow very similar boundaries as those observed from spontaneous activity. If olivary gap junctions are concentrated in glomeruli (Sotelo et al., 1974), olivary neurons receiving common synaptic drive might contribute to a single microband of PCs with well defined anatomical boundaries. The similarity suggests that, in our experiments, external excitatory drive is not sufficient to overcome the synchronizing effects of electrical coupling. However, under some conditions, microband structure might be modulated by external excitation, as well as reciprocal inhibitory input from the cerebellar nuclei to the inferior olive (de Zeeuw et al., 1989; Lang, 2002). Consistent with this idea, we found that pairs of neighboring bands were more strongly correlated and had more similar probabilities of sensory response than more widely spaced microbands. It remains to be seen whether temporal variation in nuclear firing can modulate synchronization across multiple microbands.
Microbands fit into the microzone model of cerebellar organization (Oscarsson, 1979), in which projections among the inferior olive, PCs, and deep nuclei are thought to form precisely interconnected modules that can work separately or in concert (Welsh et al., 1995; Lang et al., 1996). A teaching role for the CF pathway has been suggested by the fact that it drives associative long-term plasticity at PC synapses after many pairings (Wang et al., 2000; Coesmans et al., 2004). Microband synchrony provides information in a single trial that could be useful for online function and also provide a teaching signal to the deep nuclei (Ohyama et al., 2006). Synchrony-based coding suggests that moment-to-moment guidance and teaching may coexist as roles for the inferior olive in processing sensation and refining movement and cognition.

\section{References}

Alvarez-Otero R, Perez SE, Rodriguez MA, Anadón R (1996) Organisation of the cerebellar nucleus of the dogfish, Scyliorhinus canicula L.: a light microscopic, immunocytochemical, and ultrastructural study. J Comp Neurol 368:487-502.

Apps R, Garwicz M (2005) Anatomical and physiological foundations of cerebellar information processing. Nat Rev Neurosci 6:297-311.

Bell CC, Kawasaki T (1972) Relations among climbing fiber responses of nearby Purkinje Cells. J Neurophysiol 35:155-169.

Bengtsson F, Jörntell H (2007) Ketamine and xylazine depress sensoryevoked parallel fiber and climbing fiber responses. J Neurophysiol 98: 1697-1705.

Brown IE, Bower JM (2001) Congruence of mossy fiber and climbing fiber tactile projections in the lateral hemispheres of the rat cerebellum. J Comp Neurol 429:59-70.

Caddy KW, Biscoe TJ (1979) Structural and quantitative studies on the normal C3H and Lurcher mutant mouse. Philos Trans R Soc Lond B Biol Sci 287:167-201.

Chen G, Hanson CL, Ebner TJ (1996) Functional parasagittal compartments in the rat cerebellar cortex: an in vivo optical imaging study using neutral red. J Neurophysiol 76:4169-4174.

Coesmans M, Weber JT, De Zeeuw CI, Hansel C (2004) Bidirectional parallel fiber plasticity in the cerebellum under climbing fiber control. Neuron 44:691-700.

Cruikshank SJ, Hopperstad M, Younger M, Connors BW, Spray DC, Srinivas M (2004) Potent block of Cx36 and Cx50 gap junction channels by mefloquine. Proc Natl Acad Sci U S A 101:12364-12369.

de Montigny C, Lamarre Y (1973) Rhythmic activity induced by harmaline in the olivo-cerebello-bulbar system of the cat. Brain Res 53:81-95.

Devor A, Yarom Y (2002) Electrotonic coupling in the inferior olivary nucleus revealed by simultaneous double patch recordings. J Neurophysiol 87:3048-3058.

de Zeeuw CI, Holstege JC, Ruigrok TJ, Voogd J (1989) Ultrastructural study of the GABAergic, cerebellar, and mesodiencephalic innervation of the cat medial accessory olive: anterograde tracing combined with immunocytochemistry. J Comp Neurol 284:12-35.

D’haeseleer P (2005) How does gene expression clustering work? Nat Biotechnol 23:1499-1501.

Dunbar RL, Chen G, Gao W, Reinert KC, Feddersen R, Ebner TJ (2004) Imaging parallel fiber and climbing fiber responses and their short-term interactions in the mouse cerebellar cortex in vivo. Neuroscience 126:213-227.

Gilbert PF, Thach WT (1977) Purkinje cell activity during motor learning. Brain Res 128:309-328.

Gould BB, Rakic P (1981) The total number, time or origin and kinetics of proliferation of neurons comprising the deep cerebellar nuclei in the rhesus monkey. Exp Brain Res 44:195-206.

Groenewegen HJ, Voogd J, Freedman SL (1979) The parasagittal zonation within the olivocerebellar projection. II. Climbing fiber distribution in the intermediate and hemispheric parts of cat cerebellum. J Comp Neurol 183:551-601.

Hartigan JA, Wong MA (1979) Algorithm AS 136: a k-means clustering algorithm. Appl Stat 28:100-108.

Herrup K, Kuemerle B (1997) The compartmentalization of the cerebellum. Annu Rev Neurosci 20:61-90. 
Hopfield JJ, Brody CD (2001) What is a moment? Transient synchrony as a collective mechanism for spatiotemporal integration. Proc Natl Acad Sci U S A 98:1282-1287.

Hrycyshyn AW, Ghazi H, Flumerfelt BA (1989) Axonal branching of the olivocerebellar projection in the rat: a double-labeling study. J Comp Neurol 284:48-59.

Ito M (2001) Cerebellar long-term depression: characterization, signal transduction, and functional roles. Physiol Rev 81:1143-1195.

Ito M, Kano M (1982) Long-lasting depression of parallel fiber-Purkinje cell transmission induced by conjunctive stimulation of parallel fibers and climbing fibers in the cerebellar cortex. Neurosci Lett 33:253-258.

Johnston LE (2005) Scaling up the cerebellar network: quantitative interspecies comparisons of neuronal structure. Undergraduate thesis, Department of Psychology, Princeton University.

Kitazawa S, Kimura T, Yin PB (1998) Cerebellar complex spikes encode both destinations and errors in arm movements. Nature 392:494-497.

Lang EJ (2002) GABAergic and glutamatergic modulation of spontaneous and motor-cortex-evoked complex spike activity. J Neurophysiol 87:1993-2008.

Lang EJ, Sugihara I, Llinás R (1996) GABAergic modulation of complex spike activity by the cerebellar nucleoolivary pathway in rat. J Neurophysiol 76:255-275.

Lang EJ, Sugihara I, Welsh JP, Llinás R (1999) Patterns of spontaneous Purkinje cell complex spike activity in the awake rat. J Neurosci 19:27282739.

Llinás R, Mühlethaler M (1988) Electrophysiology of guinea-pig cerebellar nuclear cells in the in vitro brain stem-cerebellar preparation. J Physiol 404:241-258.

Llinás R, Sugimori M (1980) Electrophysiological properties of in vitro Purkinje cell dendrites in mammalian cerebellar slices. J Physiol 305:197-213.

Llinás R, Baker R, Sotelo C (1974) Electrotonic coupling between neurons in cat inferior olive. J Neurophysiol 37:560-571.

Long MA, Deans MR, Paul DL, Connors BW (2002) Rhythmicity without synchrony in the electrically uncoupled inferior olive. J Neurosci 22:10898-10905.

Maulik U, Bandyopadhyay S (2002) Performance evaluation of some clustering algorithms and validity indices. IEEE Trans Pattern Anal Mach Intell 24:1650-1654.

Miwa H (2007) Rodent models of tremor. Cerebellum 6:66-72.

Molineux ML, Mehaffey WH, Tadayonnejad R, Anderson D, Tennent AF, Turner RW (2008) Ionic factors governing rebound burst phenotype in rat deep cerebellar neurons. J Neurophysiol 100:2684-2701.

Ohyama T, Nores WL, Medina JF, Riusech FA, Mauk MD (2006) Learninginduced plasticity in deep cerebellar nucleus. J Neurosci 26:12656-12663.

Oscarsson O (1979) Functional units of the cerebellum: sagittal zones and microzones. Trends Neurosci 2:144-145.

Ozden I, Lee HM, Sullivan MR, Wang SS-H (2008) Identification and clustering of event patterns from in vivo multiphoton optical recordings of neuronal ensembles. J Neurophysiol 100:495-503.

Palay SL, Chan-Palay V (1974) Cerebellar cortex: cytology and organization. Berlin: Springer.

Palkovits M, Mezey E, Hámori J, Szentágothai J (1977) Quantitative histological analysis of the cerebellar nuclei in the cat. I. Numerical data on cells and on synapses. Exp Brain Res 28:189-209.
Pijpers A, Voogd J, Ruigrok TJ (2005) Topography of olivo-cortico-nuclear modules in the intermediate cerebellum of the rat. J Comp Neurol 492:193-213.

Ross WN, Werman R (1987) Mapping calcium transients in the dendrites of Purkinje cells from the guinea-pig cerebellum in vitro. J Physiol 389:319-336.

Sasaki K, Bower JM, Llinás R (1989) Multiple Purkinje cell recording in rodent cerebellar cortex. Eur J Neurosci 1:572-586.

Sato Y, Miura A, Fushiki H, Kawasaki T (1992) Short-term modulation of cerebellar Purkinje cell activity after spontaneous climbing fiber input. J Neurophysiol 68:2051-2062.

Simpson JI, Wylie DR, De Zeeuw CI (1996) On climbing fiber signals and their consequence(s). Behav Brain Sci 19:384-398.

Singer W, Gray CM (1995) Visual feature integration and the temporal correlation hypothesis. Annu Rev Neurosci 18:555-586.

Sotelo C, Llinás R, Baker R (1974) Structural study of inferior olivary nucleus of the cat: morphological correlates of electrotonic coupling. J Neurophysiol 37:541-559.

Steuber V, Mittmann W, Hoebeek FE, Silver RA, De Zeeuw CI, Häusser M, De Schutter E (2007) Cerebellar LTD and pattern recognition by Purkinje cells. Neuron 54:121-136.

Stone LS, Lisberger SG (1986) Detection of tracking errors by visual climbing fiber inputs to monkey cerebellar flocculus during pursuit eye movements. Neurosci Lett 72:163-168.

Sugihara I, Shinoda Y (2007) Molecular, topographic, and functional organization of the cerebellar nuclei: analysis by three-dimensional mapping of the olivonuclear projection and aldolase C labeling. J Neurosci 27:9696-9710.

Sugihara I, Wu H, Shinoda Y (1999) Morphology of single olivocerebellar axons labeled with biotinylated dextran amine in the rat. J Comp Neurol 414:131-148.

Sugihara I, Wu HS, Shinoda Y (2001) The entire trajectories of single olivocerebellar axons in the cerebellar cortex and their contribution to cerebellar compartmentalization. J Neurosci 21:7715-7723.

Sullivan MR, Nimmerjahn A, Sarkisov DV, Helmchen F, Wang SS-H (2005) In vivo calcium imaging of circuit activity in cerebellar cortex. J Neurophysiol 94:1636-1644.

Tank DW, Sugimori M, Connor JA, Llinás RR (1988) Spatially resolved calcium dynamics of mammalian Purkinje cells in cerebellar slice. Science 242:773-777.

Urbano FJ, Leznik E, Llinás RR (2007) Modafinil enhances thalamocortical activity by increasing neuronal electrotonic coupling. Proc Natl Acad Sci U S A 104:12554-12559.

Voogd J, Glickstein M (1998) The anatomy of the cerebellum. Trends Neurosci 21:370-375.

Wang SS, Denk W, Häusser M (2000) Coincidence detection in single dendritic spines mediated by calcium release. Nat Neurosci 3:1266-1273.

Welsh JP, Lang EJ, Suglhara I, Llinás R (1995) Dynamic organization of motor control within the olivocerebellar system. Nature 374:453-457.

Wylie DR, De Zeeuw CI, Simpson JI (1995) Temporal relations of the complex spike activity of Purkinje cell pairs in the vestibulocerebellum of rabbits. J Neurosci 15:2875-2887. 